\title{
Acidic pretreatment of cellulose for bio methane production
}

\author{
Mahmood Ajel ${ }^{1}$, Fawziea M. Hussien ${ }^{2}$, Johain J. Faraj ${ }^{3}$ \\ 1 Master's Research Middle Technical University Engineering Technical College-Baghdad, Baghdad \\ Iraq, \\ hussainali1983ali@gmail.com \\ 2 Asst. Prof. Middle Technical University Engineering Technical College-Baghdad, Baghdad \\ Iraq, Fawizea_material@mtu.edu.iq \\ 3Asst. Prof. Middle Technical University Engineering Technical College-Baghdad, Baghdad \\ Iraq, Johaintech@mtu.edu.iq
}

\begin{abstract}
Present work deals with the exhaustive investigations of rapid de-lignification processes from source-sorted organic fractions that are recalcitrant in nature. Organic solid wastes (OSW) belong to the organic fraction of municipal solid wastes (MSW) and they act as enormous potential substrate for alternative source of energy in the form of bio-fuels. Nevertheless, these substrates are not easily biodegradable and the degree of biodegradability is solely dependent on the composition and characteristic of organic solid wastes in municipal solid wastes. The component responsible for recalcitrance of organic solid wastes is lignin that occurs in variable amounts in different plant residues. In order to remove the recalcitrance from organic fraction municipal solid wastes and to make it more easily degradable by microbial groups, certain pretreatment techniques have been adopted and they are applied either individually or in combined way for enhancement of anaerobic digestion (AD) process.

The present work studied the effect of acid treatment with acetic acid on the used substrate, evaluated its effectiveness on biogas production, and studied the concentrations of $\mathrm{CH} 4$ and $\mathrm{CO} 2$ during the fermentation period, which amounted to 90 days. All results are presented in clear curves for the purpose of facilitating the study.
\end{abstract}

\section{1- INTRODUCTION}

Evolution, prosperity, urbanization, and rushed time wheel, all of these development aspects have their abuses. Major issues can be represented in that the beautiful world has been suffering the breakdown of its ecosystem with very serious environmental and health problems. The increase of greenhouse gases (GHGs) emissions indicates a mounting threat of climate change results in the global warming[1]. Due to prevention of these accumulated gases in the atmospheric envelop, the solar radiation trapped by the Earth's surface from reemitting again [2]. 
Carbon dioxide is the first greenhouse gas responsible of the global warming. In addition, there are enormous types of pollutants generated from large number of industrial processes in the world which contribute to global warming. This situation has committed decision makers, policies, agencies, academic sector meet the challenges to find alternative, sustainable and environmentally friendly energy sources. So, Clean Energy Technology (CET) has been established to fulfill these demands. In recent years, due to the adverse effects of conventional fuel on the environment as well as their cost escalation, the use of renewable energy sources for power generation has been seriously considered [3].

\section{2- Materials and Methodology}

\subsection{Experimental Setup}

In this work, anaerobic digesters were used, four digesters made of plastic, each digesting capacity of 30 liters, As shown in Figure (1). Three holes were made in each digester. The first hole is 2 inches in diameter and used to enter waste, the second is 1.5 inches in diameter to extract waste, and the third hole is 1 inch in diameter to extract gases in the gas collection tank.

The fermentation process was carried out at room temperature, i.e., under uncontrolled conditions, and sensors were connected for the purpose of measuring carbon dioxide and methane concentrations, temperatures and $\mathrm{pH}$ in each digester on a daily basis throughout the test period.

For the purpose of calculating the changes that occur in the four digesters, all sensors were connected to the Arduino Mega device to calculate the production of $\mathrm{CH} 4$ and $\mathrm{CO} 2$ gas and temperatures in each digester and record the results on a daily basis.

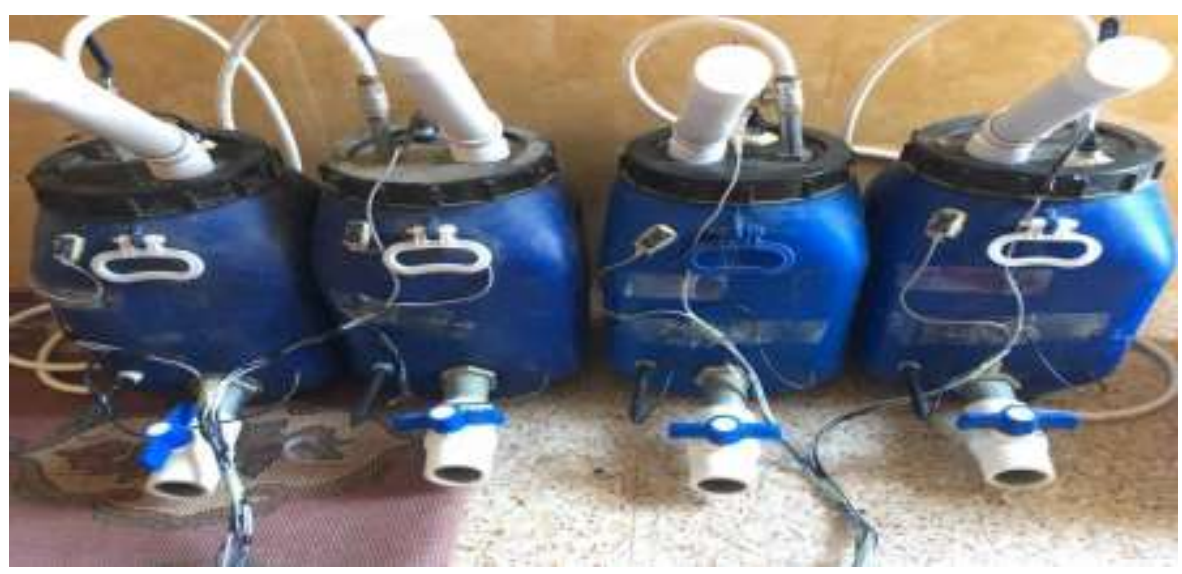

Figure (1) The device used during anaerobic digestion

\subsection{Substrate Samples Preparation}

During this study, the giant reed (GR) was relied on as a substrate during the anaerobic digestion process after mechanical and acid treatment was performed on it, and an appropriate vaccine cow 
dung (CD) was added for the purpose of accelerating the production process and ensuring the success of the process.

\subsubsection{Physical pretreatment:}

This was done using a knife and an electric mixer. The goal was to reduce the particle size in the range of 1-2 $\mathrm{mm}$. The size of this particle increases the usable area for cell enzymes to invade biomass resulting in faster degradation. It also improves mixing efficiency.

\subsubsection{Chemical pretreatment}

In this test acetic acid was used for the purpose of processing (GR). Three different concentrations were used and the chemical treatment was started according to the steps described below

- Four flasks are prepared for filling with water in equal proportions

- (GR) was placed inside the beakers

- Acetic acid was added to the flasks until the $\mathrm{pH}$ value was reached in the first flask (5), the second flask (6) and the third flask (7), while the fourth flask was not treated.

- $\quad$ Soak (GR) for 24 hours.

- After soaking, (GR) is placed in the sun to dry.

After drying (GR) is placed in four digesters with water and (CD) inoculum in equal proportions as shown in Table (1) and then the digesters are closed tightly.

Table No. (1) shows the proportions of the components of the substrate

\begin{tabular}{|c|c|c|c|}
\hline Features & giant reed (GR) & water & cow dung $(\mathrm{CD})$ \\
\hline Digesters $(1,2,3$, and 4$)$ & $4 \mathrm{~kg}$ & $8 \mathrm{~kg}$ & $4 \mathrm{~kg}$ \\
\hline
\end{tabular}

In each digestion, inert gas (nitrogen) was added for 10 minutes in order to expel all the oxygen from inside the digesters to create an anaerobic environment during the fermentation process.

Table No (2) shows the ratio of acid treatment by acetic acid to (GR) in each digestion

\begin{tabular}{|c|c|c|c|c|}
\hline Digester NO & 1 & 2 & 3 & 4 \\
\hline $\mathrm{pH}$ value during acid treatment & 5 & 6 & 7 & Without pretreatment \\
\hline
\end{tabular}

\section{Results and Discussion}

Figure (2) shows the production of $\mathrm{CO} 2$ and by observing Figure (3) it is noted that the $\mathrm{pH}$ value began to decrease during the first few weeks and this decrease in the $\mathrm{pH}$ value leads to an increase in carbon dioxide. The low $\mathrm{pH}$ value was due to acid formation in the early stages of the 
product. The carbon dioxide concentration begins to decrease gradually as methane production increases and the $\mathrm{pH}$ value increases[4].

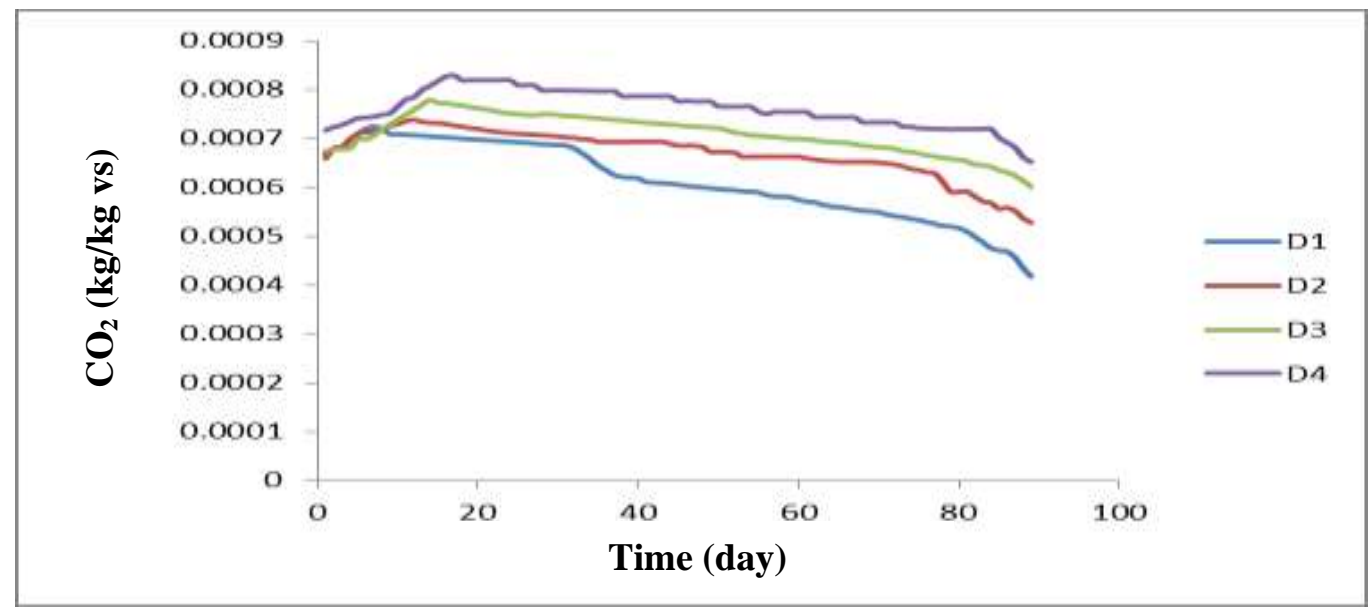

Figure (2) $\mathrm{CO} 2$ production through time

Figure (3) shows the fluctuations of the $\mathrm{pH}$ value, where we notice a decrease in the $\mathrm{pH}$ of digestion in the early stages of the digestion process, because the bacteria generate acid and then the $\mathrm{pH}$ value begins to increase gradually. During this period the $\mathrm{pH}$ has a direct relationship with biogas because an increase in the $\mathrm{pH}$ value means an increase in biogas production, but when it rises significantly the biogas begins to decrease. The $\mathrm{pH}$ value during the digestion period was from (5.8 to 7.9) where the $\mathrm{pH}$ value obtained at the end of the experiment was 7.8 (D1), 7 (D2), 8 (D3) and 7.4 (D4) which are acceptable for biogas production[5].

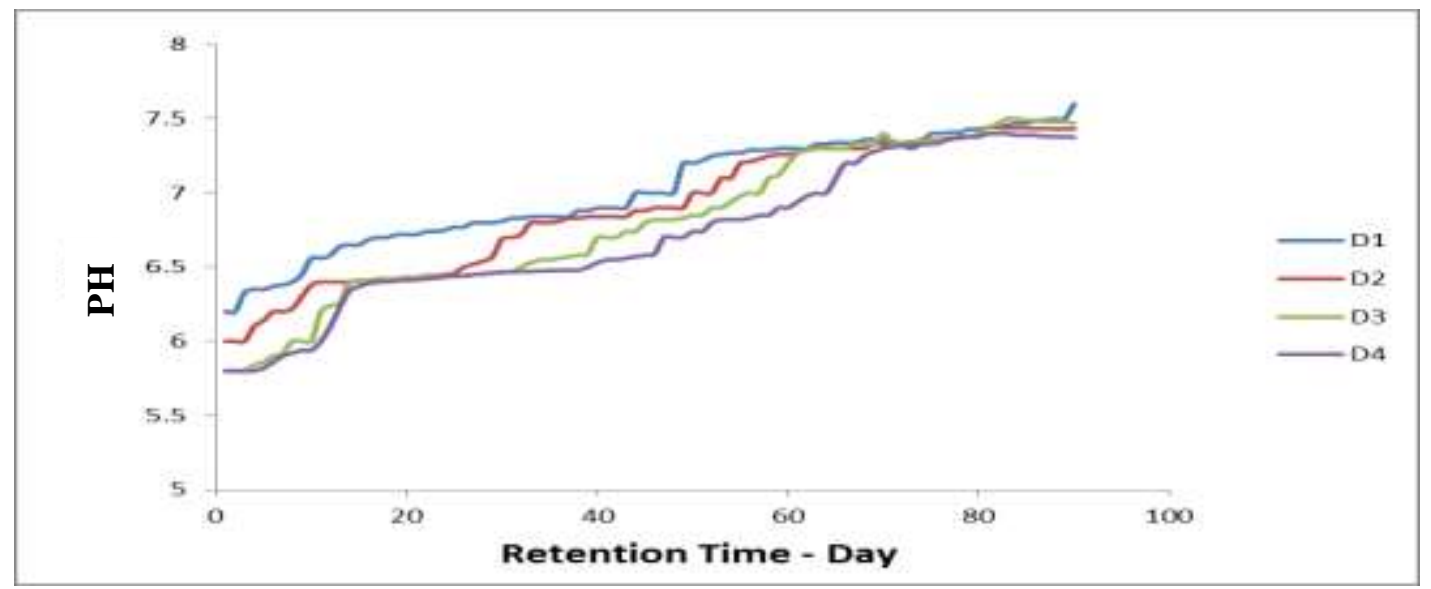

Figure (6) $\mathrm{pH}$ value through time

The acid treatment performed on the substrate in the four digesters resulted in a difference in The production of methane gas, as shown in Figure (4), where it was noted that the first digester had the highest production, because the acid treatment breaks the structure of Lignin disrupts the crystal structure of cellulose, which helps enzymes to Quick and easy access to cellulose and working to break it down [6]. 


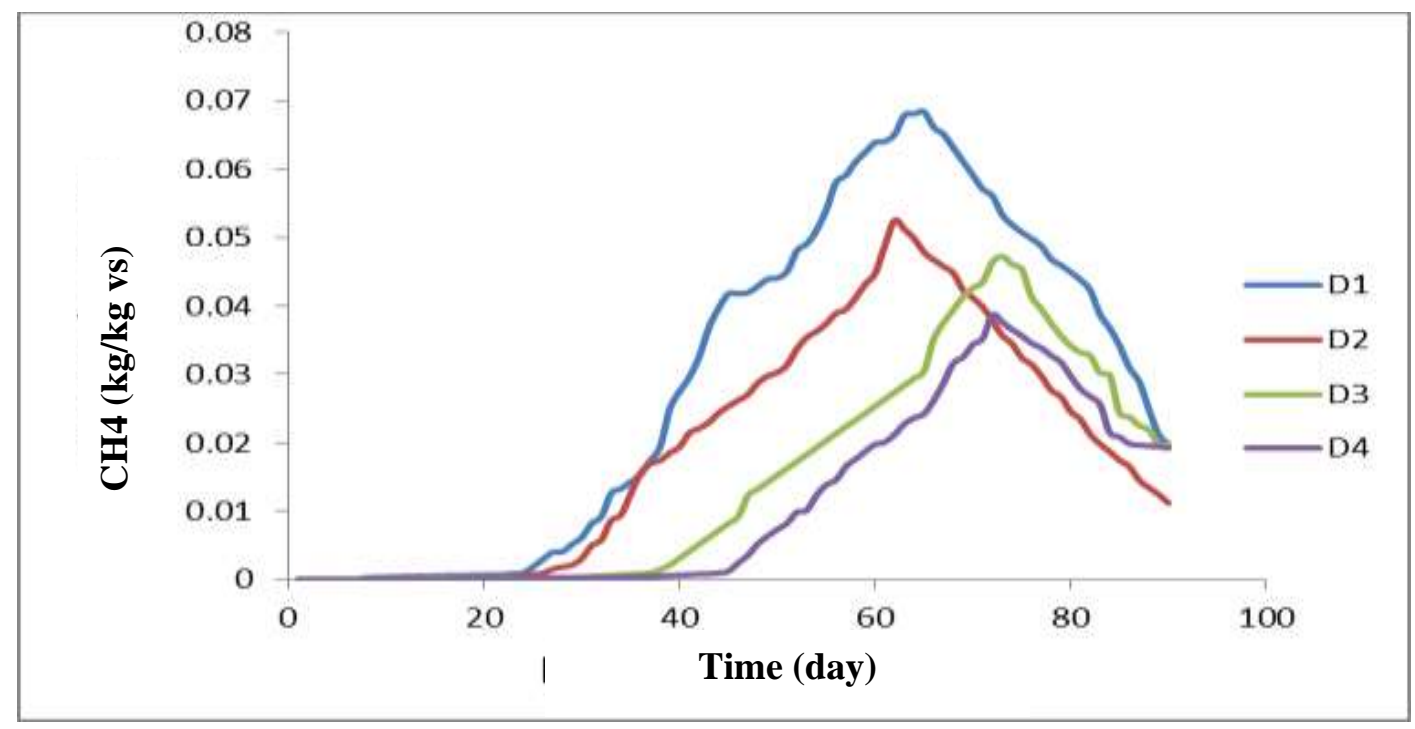

Figure (5) Methane production through time

Through the observation of Figure (5), it becomes clear to us the effect of temperature on the production of biogas, as we notice that the first digester, which has the highest production of biogas, has the highest temperatures compared with other digesters, then the second, third and fourth digesters, respectively[7].

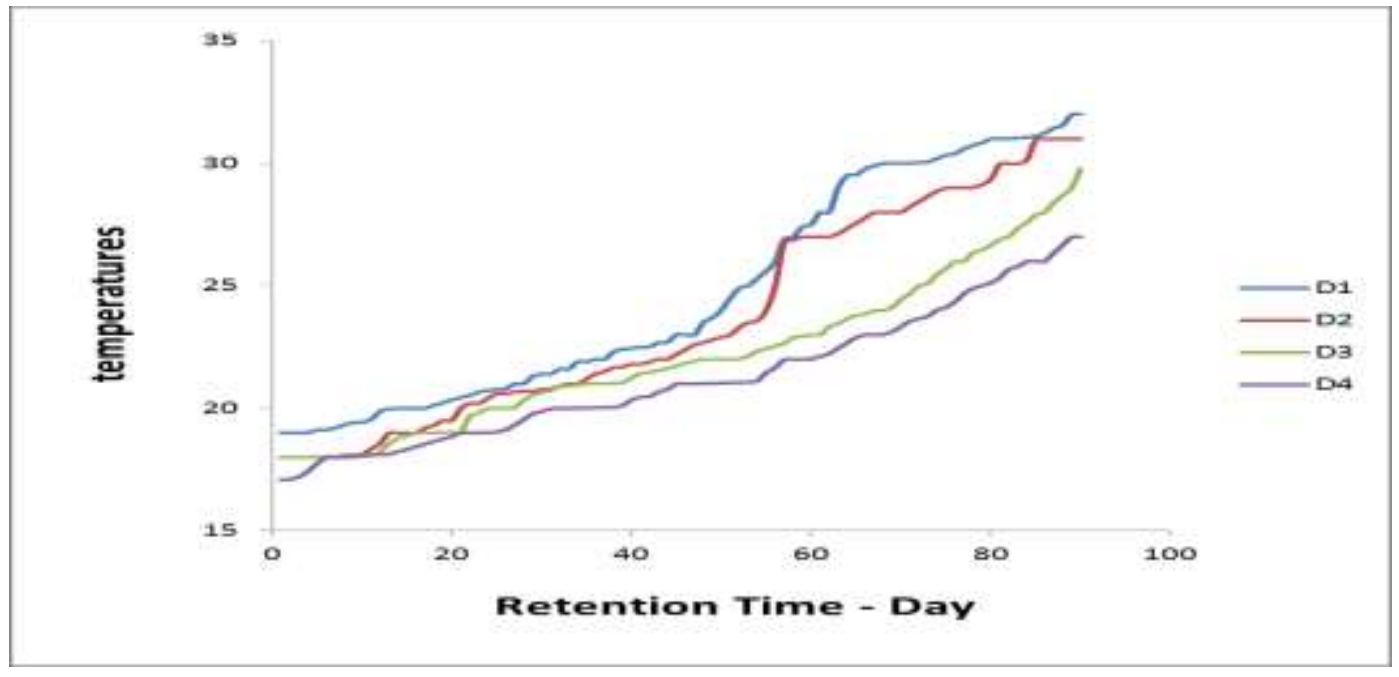

Figure (3) shows temperature changes over time

\section{4-Conclusions}

The aim of the study is to measure the effect of acid pretreatment with different concentrations of acetic acid for 24 hours on the substrate consisting of (GR) with the addition of quantities of vaccine $(\mathrm{CD})$ on the quantity and quality of biogas generated during this 90 day experiment. The 
results showed that the best biogas production and the best daily methane production were when using acid pretreatment when the $\mathrm{pH}$ value was 4.5 and for 24 hours.

\section{Acknowledgements}

I would like to appreciate and express my sincere thanks and deep gratitude to my supervisor Dr. Fawziea M. Hussein and Dr. Johain J. Faraj for incessant guidance, constant support, understanding throughout the present work, encouragement, suggestions and utmost effort and interest through the work that contributed in its completeness.

Nomenclature:
$\mathrm{AD}$
Anaerobic Digestion
$\mathrm{CD}$
Cow Dung
GR
Giant Reed

\section{References:}

[1] A. Anwar, M. Younis, and I. Ullah, "Impact of urbanization and economic growth on CO2 emission: A case of far east Asian countries," Int. J. Environ. Res. Public Health, vol. 17, no. 7, 2020, doi: 10.3390/ijerph17072531.

[2] A. Zolghadr, M. Escrochi, and S. Ayatollahi, "Temperature and composition effect on CO2 miscibility by interfacial tension measurement," J. Chem. Eng. Data, vol. 58, no. 5, pp. 1168-1175, 2013.

[3] R. Kaur and J. Vaish, "A New Era in electricity production using renewable sources," Gas, vol. 18, pp. 9-18, 2013.

[4] K. F. Adekunle and J. A. Okolie, "A review of biochemical process of anaerobic digestion," 2015.

[5] S. K. Khanal, Anaerobic Biotechnology for Bioenergy Production: Principles and Applications. 2009.

[6] N. Mosier et al., "Features of promising technologies for pretreatment of lignocellulosic biomass," 2005.

[7] R. Ramaraj and Y. Unpaprom, "Effect of temperature on the performance of biogas production from Duckweed," 2016. 